\title{
"Missing Breakfast, Sleep and Exercise: Are You Skipping Out Years of Life"
}

\author{
Sajjad A*, Anwer MO, Anwer S, Zaidi SAA and Hasan A \\ Civil Hospital Karachi, Baba-e-Urdu Road, Karachi, Pakistan
}

${ }^{*}$ Corresponding author: Sajjad A, Civil Hospital Karachi, Baba-e-Urdu Road, Karachi, Pakistan, E-mail: ass4ssin15@gmail.com

Citation: Sajjad A, Anwer MO, Anwer S, Zaidi SAA, Hasan A (2014) "Missing breakfast, sleep and exercise: are you skipping out years of life”. J Nutr Health Sci 1(3): 308. doi: 10.15744/2393-9060.1.308

Received Date: August 25, 2014 Accepted Date: November 05, 2014 Published Date: November 07, 2014

\begin{abstract}
Objective: People who regularly have breakfast are a third less likely at risk, of being obese than those who are breakfast skippers. The study aims to find the relationship between breakfast and sleeping habits with adiposity among medical students.

Design: Single center cross sectional study at a medical college of Karachi. The study was conducted from July 2011 till November 2011. We collected sample from students of each year of medical school. Convenient sampling was implied for the collection of data.

Setting: Karachi, Pakistan.

Results: Mean age of participants was $20.85 \pm 0.9$ years, while mean BMI of participants was $24.7 \pm 6.31 \mathrm{~kg} / \mathrm{m}^{2}$. Average physical activity was $208 \mathrm{~min} /$ week $\pm 92 \mathrm{~min} /$ week, while average sleep duration was 7.1 hours \pm 3.9 hours. We observed that females (63.4\%, $71 / 112)$ tend to skip breakfast around twice more than males $(27.9 \%, 34 / 122)$. People who took breakfast were found to be more physically active then those who skipped breakfast. Participants who had regular breakfast were found to have a lower BMI than those who did not.

Conclusion: Since it was found that a regular consumption of breakfast not only lowers BMI but also makes a person more physically fit. Therefore it is recommended to start the day with a healthy breakfast having all the essential nutrients.
\end{abstract}

\section{Introduction}

The importance of the undeniable fact cannot be overstated that epidemic of obesity has been shrouding developing countries after developed one, making them suffer double burdens of two extreme ranges of malnutrition with additional gradual global nutritional transition from the healthy nutritious diet into the literally junk based "fast food" pattern [1]. The terms "Obesity" and "Body Mass Index" (BMI) go hand in hand. BMI is frequently used, easy to measure and fairly reliable indicator of body fat percentage which reasonably predicts morbidity and mortality associated with higher body fat content. Higher values of BMI are significantly associated with increased risk of hypertension, heart diseases, stroke, diabetes, arthritis, breathing problems and certain types of cancers and thus reduced life expectancy $[2,3]$.

Breakfast which literally means breaking-the-fast of the night, refers to the first meal taken in the morning and is usually consumed before the start of the day. It is unarguably considered the meal of utmost importance. It is considered to play a crucial role in maintaining the physical health and intellectual capabilities of a person. Breakfast is the central component of one's daily nutritional requirement, contributing significantly to the total daily energy and nutrient intake [3]. In a study conducted by Belloc et al., regular breakfast consumers were reported to show significantly better physical health than those who skipped breakfast [4]. A.P. Smith in multiple studies reported that breakfast contributes to well-being in multiple aspects, it is claimed to affect behavioral, affective and cognitive aspects of a person's health. Individuals who consume a cereal breakfast each day are less depressed, less emotionally distressed and have lower levels of perceived stress $[5,6]$.

Breakfast skipping has been contended to have deleterious effects upon various physical and mental aspects. Numerous studies have found that breakfast skippers have relatively worse intake of various vitamins and minerals and nutrients that are lost as a result of skipping breakfast cannot be compensated by any meal of the day [7]. Breakfast, despite making noteworthy nutritional contribution to dietary quality and overall health, unfortunately is, more commonly missed than any other meal [8]. Previous studies have found that breakfast consumption has declined in all age groups over the past 25 years [9].

Adequate amount of sleep is also important for one's mental and physical health, for cognitive restitution, processing, learning and memory consolidation [10]. People who sleep less are more prone to emotional instability, cognitive dysfunction, decreased concentration, memory loss, day time sleepiness, decreased concentration and most important problem of our concern here obesity, thus inadequate sleep effects our health in a similar manner as skipping breakfast does with both short and long term influences on our wellbeing [11]. 
The aim of the study is to find the relationship between breakfast and sleeping habits with adiposity among medical students in order to encourage healthy practice of regular breakfast intake and a good eight hour sleep everyday. Hectic schedule and tiring studies easily thrust healthy routine to unhealthy ones leading to multiple problems later in life.

\section{Material and Methods}

We define breakfast as any meal taken between 6 a.m. mornings to 12 p.m. noon after waking up from overnight sleep, all meals taken after 12 p.m were considered lunch and excluded from breakfast category, the cases of multiple meals before 12 p.m. noon were also discarded to prevent complexity and confounding by multiple breakfast meals.

\section{Study Design}

We conducted a single centre cross sectional study at a medical college of Karachi. The study was conducted from July 2011 till November 2011. We collected sample from students of each year of medical school. Questionnaires were distributed to and recollected from medical students during break times between classes in non-purposive manner. Convenient sampling technique was implied for the collection of data.

\section{Sample Size}

Sample size was calculated by using Open-Epi Epidemiological Calculator by keeping anticipated frequency of $57 \%$ and confidence interval 95\% [12]. The sample size was calculated to be 194. Researchers were able to collect data from 234 students. All those who regularly took breakfast and all those who never had a history of taking breakfast were included in the study. Those who seldom had their breakfast were excluded from the study.

\section{Ethical consideration}

Written informed consent was obtained from the participants after explaining the study objectives. The participants were free to withdraw at any time without giving any reason. Strict confidentiality was maintained throughout the process of data collection, entry and analysis.

All efforts were made in this study to fulfill the ethical considerations in accordance with the 'Ethical principles for medical research involving human subjects' of Helsinki Declaration.

\section{Questionnaire}

A pre-designed self-administered questionnaire was used for data collection. The questionnaire was designed based on the preceding observations of investigators and recommendations from colleagues, which was further extrapolated by integration of new aspects observed during an extensive literature search. The questionnaire prepared was then pre-tested on 20 respondents and no changes were considered necessary in the questionnaire based on this pilot study. The results of the pre-testing were not incorporated in the final analysis of the data. The questionnaire comprised of following three parts:

The first part was concerned with general demographic information including age, gender and socioeconomic status while the second part inquired about their breakfast habits and their height and weight which was taken by investigators using height and weight scale on the spot, through which body mass index was calculated using standard formula given by Adolphe Quetelet and categorized using recommendation given by World Health Organization as underweight $\left(<18.5 \mathrm{~kg} / \mathrm{m}^{2}\right)$, normal $\left(18.5-24.9 \mathrm{~kg} / \mathrm{m}^{2}\right)$, overweight $\left(>25.0 \mathrm{~kg} / \mathrm{m}^{2}\right)$ and obese $\left(>30.0 \mathrm{~kg} / \mathrm{m}^{2}\right)[13]$.

The third part inquired the participants about their weekly physical activities. Moderate physical activities such as cycling, walking and aerobics were included and the amount of minutes spent per week were calculated and then grouped as credit hours of moderate physical activity according to the guidelines given by World Health Organization 2010 and Physical activity Guidelines Advisory Committee 2008 into less than 150 minutes per week and more than or equal to 150 minutes per week. Those who had an activity of $<150$ minutes per week were considered inactive/inadequate physically active and those who had $\geq 150$ minutes per week of activity were active/adequate physically active.

\section{Data entry and Analysis}

Data was entered and analyzed using SPSS version 19.0. Various statistical methods were applied for parametric and nonparametric analytics. Chi-square test was used for qualitative, while student's t-test and logistic regression analysis for quantitative variety of data. Tables were used to express the results of the study.

\section{Results}

Our study yielded that mean age of participants was $20.85 \pm 0.9$ years, while mean BMI of participants was $24.7 \pm 6.31$. Average physical activity was $208 \mathrm{~min} /$ week $\pm 92 \mathrm{~min} /$ week, while average sleep duration was 7.1 hours \pm 3.9 hours. 
Table 1 depicts the general descriptive statistics of our study. Male participants $(52.1 \%, 122 / 234)$ were marginally more compared to female $(47.9 \%, 112 / 234)$. More participants belonged to middle class $(77.8 \%, 182 / 234)$ than higher class $(22.2 \%, 52 / 234)$, while no case of low socioeconomic class was recorded. The trend of breakfast omission was $44.8 \%(105 / 234)$, while trend of mid-day snacks was observed in 57.3\% (134/234). There were 44\% (103/234) participants performing physical activity of more than 150 minutes per week, Breakfast eating time of 6 to 8 a.m. was most frequent timing $(45.7 \%, 107 / 234)$ followed by later timings. Sleep duration was most frequently distributed around 6 to 8 hours $(44.3 \%, 127 / 234)$, followed by earlier and later durations in hours. Majority of students i.e. 50.4\% (118/234) had BMI within normal range.

\begin{tabular}{|c|c|c|c|}
\hline Queries & Response & $\begin{array}{c}\text { Frequency } \\
(\mathrm{n}=234)\end{array}$ & Percentage \% \\
\hline \multirow{2}{*}{ Gender } & Male & 122 & $52.1 \%$ \\
\hline & Female & 112 & $47.9 \%$ \\
\hline \multirow{2}{*}{ Socio Economic status } & Middle & 182 & $77.8 \%$ \\
\hline & Upper & 52 & $22.2 \%$ \\
\hline \multirow{2}{*}{ Take Breakfast } & Yes & 129 & $55.2 \%$ \\
\hline & No & 105 & $44.8 \%$ \\
\hline \multirow{2}{*}{ Take mid-day snacks } & Yes & 134 & $57.3 \%$ \\
\hline & No & 100 & $42.7 \%$ \\
\hline \multirow{3}{*}{$\begin{array}{l}\text { At what time do you } \\
\text { have breakfast }\end{array}$} & $6-8$ a.m. & 59 & $45.7 \%$ \\
\hline & $8-10$ a.m. & 32 & $24.7 \%$ \\
\hline & $10-12$ a.m. & 38 & $29.6 \%$ \\
\hline \multirow{3}{*}{ How long do you sleep } & $<6$ hours & 77 & $33 \%$ \\
\hline & $6-8$ hours & 104 & $44.3 \%$ \\
\hline & $>8$ hours & 53 & $22.7 \%$ \\
\hline \multirow{2}{*}{$\begin{array}{c}\text { Physical Activity in a } \\
\text { week }\end{array}$} & $<150$ minutes & 131 & $56 \%$ \\
\hline & $\geq 150$ minutes & 103 & $44 \%$ \\
\hline \multirow{4}{*}{ BMI Ranges } & $\begin{array}{l}\text { Underweight } \\
\left(<18.5 \mathrm{~kg} / \mathrm{m}^{2}\right)\end{array}$ & 35 & $15 \%$ \\
\hline & $\begin{array}{c}\text { Normal } \\
\left(18.5-24.9 \mathrm{~kg} / \mathrm{m}^{2}\right)\end{array}$ & 118 & $50.4 \%$ \\
\hline & $\begin{array}{c}\text { Overweight } \\
\left(25-29.9 \mathrm{~kg} / \mathrm{m}^{2}\right)\end{array}$ & 55 & $23.5 \%$ \\
\hline & $\begin{array}{c}\text { Obese } \\
\left(25-29.9 \mathrm{~kg} / \mathrm{m}^{2}\right)\end{array}$ & 26 & $11.1 \%$ \\
\hline
\end{tabular}

Table 1: General descriptive statistics of study

Observing gender differential among different variables, we observed that females tend to skip breakfast $(63.4 \%, 71 / 112)$ around twice more than males $(27.9 \%, 34 / 122)$, similarly there was statistically significant lesser trend physical activity and lesser sleep duration compared to male participants as shown in Table 2.

Skipping breakfast was observed to have statistically significant associations with gender, socioeconomic status, mid-day snacking. Participants from middle socioeconomic status were found to omit breakfast marginally more compared to participants from upper class. Participants skipping breakfast consumed significantly more mid day snacks, performed less physical activities and slept for lesser duration of time, as depicted in Table 3.

Significantly lower BMI is reported in our study being associated with breakfast consumption, male gender, middle socioeconomic status and mid-day snack omission as indicated in Table 4.

Simple linear regression analysis for breakfast timing, sleep duration and physical activity show predictability and association of the variables with BMI. Statistical analysis shows that earlier breakfast, adequate sleep duration and sufficient physical activity predicted significantly lower BMI as shown in Table 5. On average 1 hour later breakfast consumption was associated with increase in mean BMI of $0.192 \mathrm{~kg} / \mathrm{m}^{2}$. Hence a difference of BMI of $1.152 \mathrm{~kg} / \mathrm{m}^{2}$ can be predicted between those who eat breakfast at 6 a.m. and those who eat breakfast at 12 a.m. Similarly average 1 hour sleep was associated with decrease in mean BMI of $0.179 \mathrm{~kg} /$ $\mathrm{m}^{2}$, hence those who sleep for 10 hours had around BMI of $0.9 \mathrm{~kg} / \mathrm{m}^{2}$ less than those who sleep for 5 hours. Average $100 \mathrm{minutes}$ moderate physical exercises were linked with decrease in mean BMI of around $0.50 \mathrm{~kg} / \mathrm{m}^{2}$. 


\begin{tabular}{|c|c|c|c|c|}
\hline \multicolumn{5}{|c|}{ Table \# 2-a: Relation of gender with breakfast skipping } \\
\hline Gender & Breakfast eaten (129) & Breakfast skipped (105) & Statistical test & p-value \\
\hline Male (122) & $88(72.1 \%)$ & $34(27.9 \%)$ & $\mathrm{X}^{2}$ test value & \\
\hline Female (112) & $41(36.6 \%)$ & $71(63.4 \%)$ & 29.79 & $<0.001$ \\
\hline \multicolumn{5}{|c|}{ Table \# 2-b: Relation of gender with physical activity } \\
\hline Gender & $\begin{array}{c}\text { Physical activity duration } \\
\text { (minutes per week) }\end{array}$ & Std. Dev. & Statistical test & p-value \\
\hline Male (122) & 289 min/week & 89 min/week & t-test value & \\
\hline Female (112) & 127 min/week & 52 min/week & 17.165 & $<0.001$ \\
\hline \multicolumn{5}{|c|}{ Table \# 2-c: Relation of gender with sleep duration } \\
\hline Gender & Sleep Duration (hours) & Std. Dev. & Statistical test & p-value \\
\hline Male (122) & 7.5 & 3.2 & t-test value & \\
\hline Female (112) & 6.7 & 2.8 & 1.267 & 0.043 \\
\hline
\end{tabular}

Table 2: Relation of Gender with breakfast pattern, physical activity and sleep duration

\begin{tabular}{|c|c|c|c|c|}
\hline Breakfast & Middle class (182) & Upper Class (52) & Statistical test & p-value \\
\hline Yes (129) & $95(52.1 \%)$ & $34(65.4 \%)$ & $\mathrm{X} 2$ test value & \\
\hline No (105) & $87(47.9 \%)$ & $18(34.6 \%)$ & 2.84 & 0.045 \\
\hline \multicolumn{5}{|c|}{ Table \# 3-b: Relation of breakfast skipping with Mid day snacks } \\
\hline \multirow{2}{*}{ Breakfast } & \multicolumn{2}{|c|}{ Mid day meals } & \multirow{2}{*}{ Statistical test } & \multirow{2}{*}{ p-value } \\
\hline & Yes (134) & No (100) & & \\
\hline Yes (129) & $59(44 \%)$ & $70(70 \%)$ & $\mathrm{X} 2$ value & \\
\hline No (105) & $75(66 \%)$ & $30(30 \%)$ & 7.24 & 0.005 \\
\hline \multicolumn{5}{|c|}{ Table \# 3-c: Relation of breakfast skipping with physical activity } \\
\hline Breakfast & $\begin{array}{l}\text { Physical activity duration } \\
\text { (minutes per week) }\end{array}$ & Std. Dev. & Statistical test & p-value \\
\hline Yes (129) & $254.9 \mathrm{~min} /$ week & $105 \mathrm{~min} /$ week & t-test value & \\
\hline No (105) & $162.1 \mathrm{~min} /$ week & $89 \mathrm{~min} /$ week & 7.193 & $<0.001$ \\
\hline \multicolumn{5}{|c|}{ Table \# 3-d: Relation of breakfast skipping with sleep duration } \\
\hline Breakfast & Sleep Duration (hours) & Std. Dev. & Statistical test & p-value \\
\hline Yes (129) & 7.7 & 3.2 & $\mathrm{t}$-test value & \\
\hline No (105) & 6.5 & 2.8 & 5.57 & 0.002 \\
\hline
\end{tabular}

Table 3: Relation of Breakfast skipping with variables

\begin{tabular}{|c|c|c|c|c|}
\hline Response & Mean BMI & Std. Deviation & Test values & p-values \\
\hline \multicolumn{5}{|c|}{ Take breakfast or not? $(\mathbf{n}=\mathbf{2 3 4})$} \\
\hline Yes (129) & 23.8 & 3.27 & t-test values & \\
\hline No (105) & 25.4 & 3.84 & -3.44 & $<0.001$ \\
\hline \multicolumn{5}{|c|}{ Gender (n= 234) } \\
\hline Male (122) & 25.9 & 7.3 & t-test values & p-values \\
\hline Female (112) & 23.5 & 6.7 & 2.39 & 0.017 \\
\hline \multicolumn{5}{|c|}{ Socio-economic status (n= 234) } \\
\hline Middle (182) & 23.7 & 4.38 & t-test value & p-value \\
\hline Higher (52) & 25.8 & 5.83 & -2.41 & 0.018 \\
\hline \multicolumn{7}{|c|}{ Mid day snacks (n= 234) } \\
\hline Yes (134) & 26.5 & 3.9 & t-test value & p-value \\
\hline No (100) & 22.9 & 3.7 & 2.15 & 0.04 \\
\hline
\end{tabular}

Table 4: Relation between BMI and variables 


\begin{tabular}{|c|c|c|c|c|c|}
\hline Variables & Beta Coefficient & R & R2 & S.E.M & p-value \\
\hline $\begin{array}{c}\text { Breakfast eating time } \\
\text { (hour) }\end{array}$ & 0.192 & 0.68 & 0.46 & 0.74 & 0.009 \\
\hline $\begin{array}{c}\text { Sleep duration } \\
\text { (hours) }\end{array}$ & -0.179 & 0.75 & 0.57 & 0.56 & 0.030 \\
\hline $\begin{array}{c}\text { Physical activity } \\
\text { (100 minutes) }\end{array}$ & -0.490 & 0.72 & 0.53 & 0.68 & $<0.001$ \\
\hline
\end{tabular}

Table 5: Simple linear regression analysis of variables with BMI

\section{Discussion}

Early sleep, early waking up, regular breakfast and light to moderate exercise all constitute healthy habits. Regrettably these habits are not very frequent among medical students, because of exceptionally tiring schedule, protracted studies and burden of performing well in medical schools.

In our study, trend of skipping breakfast among medical students was found to be around $45 \%$ which is quite higher compared to proportion of people who skipped their breakfast in studies done in Pakistan i.e. $26.3 \%$ in a study by Sheikh R.M et al [14]. A comparatively higher breakfast omission of 58.5\% was found in students of selected universities of Malaysia [15].

Females were observed to skip breakfast more likely as evident in other studies as well $[12,16]$. It is probably because of common misconception, prevalent among girls, that skipping breakfast aids in decreasing weight [16]. However a few researches, have reported males to be more frequent skipper [17].

Though in many studies no relationship has been found between BMI and breakfast eating pattern multitude of researches, including ours, confirm the finding that skipping the morning meal is associated with greater trend of adiposity [18,19]. Breakfast consumers are more likely to have lower body mass index than breakfast skippers [20]. Another interesting fact that was observed was association between the time at which the breakfast was taken and BMI. Students who took their breakfast early in the morning had lower BMI as compared to those who took it in the later part of the day. Behrens et al. in their study reports that eating soon after waking up was associated with higher dietary restraint, lower snacking and decreased eating frequencies [21].

So how does breakfast effect the physiology governing the weight dynamics? Studies have shown that the energy intake of normal and underweight persons is more evenly distributed throughout the day than that of the obese [22]. Since weight is inversely related to the number of time that a person eats during the whole day [23], the main reason anticipated to explain decreased ability to loose weight among breakfast skippers is increased frequency to indulge in snacks and other meals during the rest of the day. Similarly a significant compensatory mid-day snacking was observed in our study among breakfast skippers. Other studies also report that breakfast consumers tend to snack less often than those who are in habit of skipping breakfast [21].

There are conflicting evidences concerning relationship between breakfast consumption and social class. Multiple studies reported that economically disadvantaged participants were either found to indulge in low quality breakfast behaviors or completely skip breakfast $[7,8,24]$. It is usually considered that those with relatively low level of education are more likely to omit breakfast [25].

It has been observed that regular breakfast consumption is associated with general well being of an individual and the person is more likely to indulge in physical activity. A Finnish study reported regular breakfast eating was consistently associated with good health and the individuals were more inclined to engage in physical activity [26]. Albertson et al. reported that physical activity is closely related to significantly decreased BMI which closely relate to our findings [27].

Our study also reports that females tend to sleep less than males, probably because sleep disorders are prevalent among females [28]. Around one-third of our participants were observed to sleep less than 6 hours which is quite similar to the findings reported by Bahammam et al in which 30\% of U.S adults slept for less than 6 hours a day which increased from 23\% in 1985 [29]. However study conducted among medical students in Saudia Arabia by Abdulghani et al reported 48\% of students sleeping less than 6 hours every day [28]. Other studies state that only one-third of teens are getting recommended 9 hours of night-time sleep which is even lower in our study [30].

Our study significantly predicted inverse relation between sleep duration and BMI in a linear pattern, which can be validated from multitude of studies [31], Hence short sleep duration was associated with increased likelihood of obesity. However others report U-shaped association of sleep duration with adiposity, with shorter as well as longer duration of sleep leading to higher BMI [32]. One meta-analysis showed that for every hour less that adults sleep per night, there is a $0.35 \mathrm{~kg} / \mathrm{m}^{2}$ increase in BMI, which is almost double the BMI our study predicted [33]. Observational and experimental evidences indicate that sleep curtailment is associated with decreased secretion of leptin, increased secretion of ghrelin, increased level of cortisol and consequently increased hunger and appetite [34]. 


\section{Recommendations}

Since there are array of data endorsing benefits of eating breakfast, it is important to start ones day with a healthy, hearty breakfast [16]. A number of researchers have argued that habits are formed early in life [35] and tend to continue unchanged into adulthood [15]. Since established habits are considered difficult to alter, hence parents should focus upon introducing breakfast early in life and should continue this trend through out the childhood so that children follow this healthy routine into adulthood. Moreover parents should also emphasize on good sleeping habits because adequate amount of sleep daily is closely related to well being of a person.

\section{Limitation}

Our study did not follow any definition of breakfast previously published in relevant aspect, due to variation in participants perception regarding definition of breakfast; the study may contribute to variation in results compared to different studies and may add yet another deviant definition of breakfast in literature, thus lack of a standard definition of breakfast could be partially responsible for variation in study results [36].

The study was observational and cross-sectional type, and did not involve any randomization, experimentation or blinding, and hence no firm measure to prevent biasing was undertaken, studies based on better study designs are required to further confirm or disprove extracted facts. Since only students of single medical institute were included in study, results might not be applicable to all medical students.

\section{References}

1. Yahia N, Achkar A, Abdullah A, Rizk S (2008) Eating habits and obesity among Labanese students. Nutr J 7: $32-7$.

2. Hubert HB, Feinleib M., McNamara PM, Castelli WP (1983) Obesity as an independent risk factor for cardiovascular disease: a 26 year follow-up of participants in the Framingham Heart Study. Circulation 67: 968-77.

3. Hill GM, Greer LL, Link JE, Ellersieck MR, Dowdy RP (1991) "Influence of breakfast consumption patterns on dietary adequacy of young, low-income children.” FASEB J 245- A1644.

4. Belloc NB, Breslow L (1972) Relationship of physical health status and Health practices. Prev Med 1: 409-21.

5. Smith AP (1999) Breakfast cereal consumption and subjective reports on health. Int J Food Sci Nutr 50: 445-9.

6. Smith AP (2002) Stress, Breakfast cereal consumption and cortisol. Nutr Neurosci 5: 141-4.

7. Bidgood BA, Cameron G Meal/snack missing and dietary inadequacy of primary school children. J Canadi Diet Assoc 53: 164-8.

8. Utter J, Scragg R., Schaaf D, Fitzgerald E (2007) At-Home Breakfast Consumption among New Zealand Children: Associations with Body Mass Index and Related Nutrition Behaviors. J Am Diet Assoc 107: 570-6.

9. Keski-Rahkonen A, Kaprio J, Rissanen A, Virkkunen M, Rose RJ (2003) Breakfast skipping and health-compromising behaviors in adolescents and adults. Eur J Clin Nutr 57: 842-853.

10. Smith C (1995) Sleep states and memory processes. Behav Brain Res 69: 137-45.

11. Allan GA, Jose T, Helena AM (2012) Sleep and wake patterns and academic performance in university students. European Conference on Educational Research, university of Lisbon, Portugal 11-14.

12. Shaw ME (1998) Adolescent breakfast skipping: an Australian study. Adolescence 33: 851-61.

13. World Health Organization (2006) BMI Classification, Global Database on Body Mass Index, Geneva, Switzerland.

14. Sheikh RM, Khan HM, Shoaib N, Sheikh AM, Deeba F, et al. (2012) Relationship of Breakfast Taking Practices and Weight among Female Students of Medical Colleges of Lahore, Pakistan.

15. Alam P (2012) Nutritional Status and Eating Practices among University Students in Selected Universities in Selangor, Malaysia. Asia J Clin Nutr 4: 77-87.

16. Morgan KJ, Zabik ME, Stampley GL (1986) Breakfast consumption patterns of US children and adolescents. Nutr Res 6: 635-46.

17. McIntyre L (1993) A survey of breakfast-skipping and inadequate breakfast-eating among young schoolchildren in Nova Scotia. Can J Public Health 84: 410-4.

18. Schlundt DG, Hill JO, Sbrocco T, Pope-Cordle J, Sharp T (1992) The role of breakfast in the treatment of obesity: a randomized clinical trial. Am J Clin Nutr 55: 645-51.

19. Summerbell CD, Moody RC, Shanks J, Stock MJ, Geissler C (1996) Relationship between feeding pattern and body mass index in 220 free-living people in four age groups. Eur J Clin Nutr 50: 513-9.

20. Gibson SA, O’Sullivan KR (1995) Breakfast cereal consumption patterns and nutrient intakes of British school children. J R Soc Health 115: 336-70.

21. Behrens B (2009) Is breakfast or breakfast skipping associated with adiposity in adults? Methodological considerations.

22. Bellisle F, Rolland-Cachera MF, Deheeger M, Guilloud-Bataille M (1988) Obesity and food intake in children: evidence for a role of metabolic and/or behavioral daily rhythms. Appetite 11: 111-8.

23. Summerbell CD, Moody RC, Shanks J, Stock MJ Geissler C (1996) Relationship between feeding pattern and body mass index in 220 free-living people in four age groups. Eur J Clin Nutri 50: 513-9. 
24. Aranceta J, Sera-Majem L, Ribas L, Perez-Ridrigo C (2001) Breakfast consumption in Spanish children and young people. Public Health Nutri 4: 1439-44. 25. Cornelius LJ (1991) Health habits of school-age children. J Health Care Poor Undeserved 2: 374-95.

26. Aarnio M, Winter T, Kujala U, Kaprio J (2002) Associations of health related behavior, social relationships, and health status with persistent physical activity and inactivity: a study of Finnish adolescent twins. Br J Sports Med 36: 360-4.

27. Albertson AM, Franko DL, Thompson D, Eldridge AL, Holschuh N, et al. (2007) Longitudinal patterns of breakfast eating in black and white adolescent girls. Obesity 15: 2282-92.

28. Abdulghani HM, Alrowais NA, Bin-Saad NS, Al-Subaie NM, Haji AM, et al. (2012) Sleep disorder among medical students: Relationship to their academic performance. Med Teach 34: 37-41.

29. Bahammam AS, Al-Khairy OK, Al-Taweel AA (2005) Sleep habits and patterns among medical students. Neurosciences (Riyadh.) 10: 159-62.

30. Carskadon MA, Acebo C (2002) Regulation of sleepiness in adolescents: update, insights, and speculation. Sleep 25: 606-14.

31. Theorell-Haglow J, Berne C, Janson C, Sahlin C, Lindberg E (2010) Associations between short sleep duration and central obesity in women. Sleep 33: 593-8.

32. Anic GM, Titus-Ernstoff L, Newcomb PA, Trentham-Dietz A, Egan KM (2010) Sleep duration and obesity in a population-based study. Sleep Med 11: 447-51.

33. Cappuccio FP, Taggart FM, Kandala NB, Currie A, Peile E, et al. (2008) Meta-analysis of short sleep duration and obesity in children and adults. Sleep 31: 619-26.

34. Taheri S, Lin L, Austin D, Young T, Mignot E (2004) Short sleep duration is associated with reduced leptin, elevated ghrelin, and increased body mass index. PLoS Med 1: e62.

35. Perry CL, Griffin G, Murphy DM (1985) Assessing needs for youth health promotion. Preventive Medicine 14: 379-93

36. Kant AK, Andon MB, Angelopoulos TJ, Rippe JM (2008) Association of breakfast energy density with diet quality and body mass index in American adults: National Health and Nutrition Examination Surveys, 1999-2004. Am J Clin Nutr 88: 1396-404.

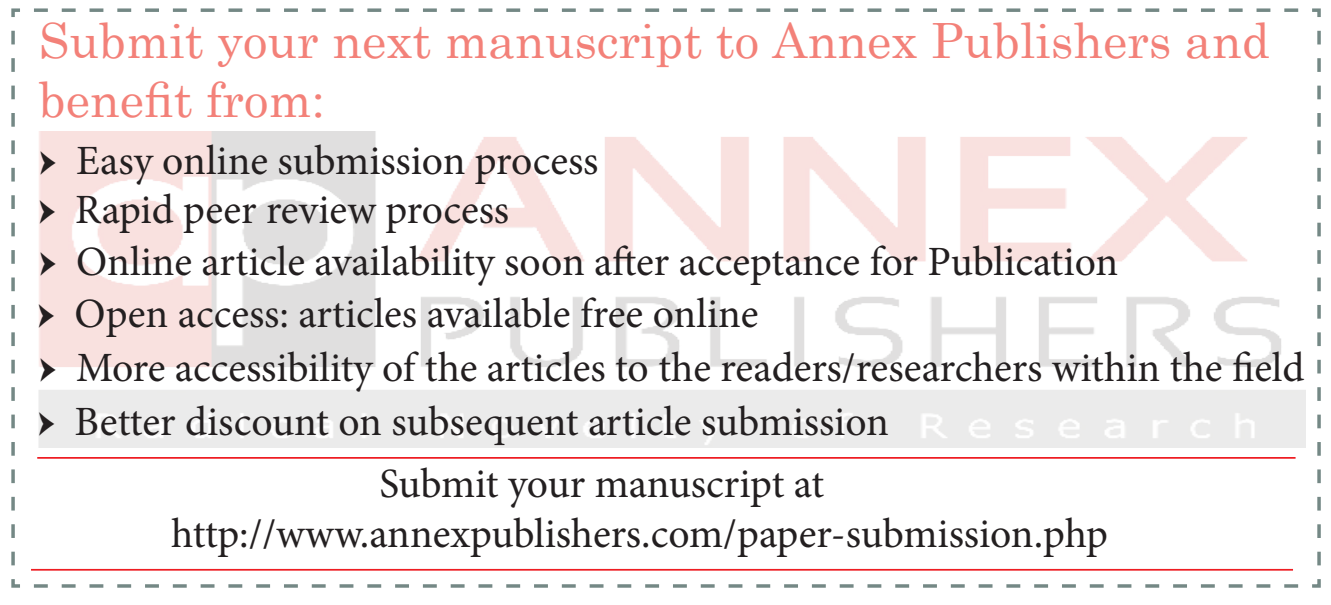

